\title{
Feasibility Demonstrations of Liquid Turbine Power Generator Driven by Low Temperature Heats
}

\author{
Seiichi Deguchi', Norifumi Isu², Hidenori Kato', Saeko Miwa1 \\ ${ }^{1}$ Department of Energy Engineering and Science, Nagoya University, Nagoya, Japan \\ ${ }^{2}$ Kitchen and Bathroom Technology Research Institute, LIXIL Corporation, Noda, Japan \\ Email: deguchi@nuce.nagoya-u.ac.jp
}

Received 26 June 2016; accepted 15 August 2016; published 18 August 2016

Copyright (C) 2016 by authors and Scientific Research Publishing Inc.

This work is licensed under the Creative Commons Attribution International License (CC BY). http://creativecommons.org/licenses/by/4.0/

(c) (i) Open Access

\begin{abstract}
Lower temperature waste heats less than $373 \mathrm{~K}$ have strong potentials to supply additional energies because of their enormous quantities and ubiquity. Accordingly, reinforcement of power generations harvesting low temperature heats is one of the urgent tasks for the current generation in order to accomplish energy sustainability in the coming decades. In this study, a liquid turbine power generator driven by lower temperature heats below $373 \mathrm{~K}$ was proposed in the aim of expanding selectable options for harvesting low temperature waste heats less than $373 \mathrm{~K}$. The proposing system was so simply that it was mainly composed of a liquid turbine, a liquid container with a biphasic medium of water and an underlying water-insoluble low-boiling-point medium in a liquid phase, a heating section for vaporization of the liquid and a cooling section for entropy discharge outside the system. Assumed power generating steps via the proposing liquid turbine power generator were as follows: step 1: the underlying low-boiling-point medium in a liquid phase was vaporized, step 2: the surfacing vapor bubbles of low-boiling-point medium accompanied the biphasic medium in their wakes, step 3: such high momentum flux by step 2 rotated the liquid turbine (i.e. power generation), step 4: the surfacing low-boiling-point medium vapor was gradually condensed into droplets, step 5: the low-boiling-point medium droplets were submerged to the underlying medium in a liquid phase. Experiments with a prototype liquid turbine power generator proved power generations in accordance with the assumed steps at a little higher than ordinary temperature. Increasing output voltage could be obtained with an increase in the cooling temperature among tested ranging from 294 to $296 \mathrm{~K}$ in contrast to normal thermal engines. Further improvements of the direct current voltage from the proposing liquid turbine power generator can be expected by means of far more vigorous multiphase flow induced by adding solid powders and theoretical optimizations of heat and mass transfers.
\end{abstract}




\section{Keywords}

\section{Liquid Turbine Power Generator, Low Temperature Heats Recovery, Phase Changes, Biphasic Medium, Energy Harvesting Technology}

\section{Introduction}

The current generation is faced with many crucial problems such as global warming, loss of biodiversity and exhaustion of fossil fuels. Among these issues, fossil fuels' exhaustion must be the most urgent threat, and needs to be solved in order to ensure the survival of mankind as soon as possible.

Lower temperature waste heats less than $373 \mathrm{~K}$ have strong potentials to supply additional energies because of their enormous quantities and ubiquity throughout the world. However, such low temperature waste heats are generally treated to be unfit as efficient sources for power generations since they have quite high entropy, and then a large portion of them is just wasted as their appellation suggests. Therefore, the authors have been focused on applying thermal spontaneous phenomena driven by low temperature heats to intelligent materials for creating significant energy harvesting technologies from lower temperature waste heats less than $373 \mathrm{~K}$. Table 1 shows representative examples of developed and/or developing low temperature waste heats recovering technologies by the authors for a sustainable energy platform.

Among described in Table 1, there is no investigation concerning the liquid turbine power generation via low temperature heats in contrast to enormous lambent outcomes for the former two technologies [7]-[13].

This paper introduces a prototype liquid turbine power generator manufactured by way of its feasibility demonstrations. And, experimental proofs are discussed in details so as to specify the significances of the proposing liquid turbine power generator harvesting low temperature heats.

\section{Experimental}

\subsection{Experimental Apparatus and Operating Medium}

Figure 1 shows a schematic drawing of the prototype liquid turbine power generator. A column-shaped liquid container made of transparent acrylic resin with $700 \mathrm{~mm}$ in height and $185 \mathrm{~mm}$ in diameter contains a liquid turbine pulled out from the commercial air multiplier (KA1-JP, DYSON Limited), a plug heater with $90 \mathrm{~mm}$ in height (NPC-120, Nakanihon Heater Co., LTD.) at the bottom, a vena contract a and an operating medium.

As shown in Figure 1, a biphasic medium of water and an underlying water-insoluble low-boiling-point liquid, which is Novec merchandised by 3M Japan Limited [14] [15], has been selected as the operating medium. Table 2 shows quite unique properties of Novec, comparing with water and other investigated candidates as the operating medium.

It can be seen that Novec has the lowest boiling point, the lowest specific heat and the lowest latent heat of vaporization among the investigated. Consequently, vigorous flow of Novec induced by its phase changes under lower heating flux and temperature has been plainly predicted even if it had been utilized in a monophasic state as the operating medium for the proposing liquid turbine power generator. However, Novec is too expensive about $\$ 100 \mathrm{~kg}^{-1}$, and it has quite a low convective heat transfer coefficient about one sixth to water [14]. Taking a high specific density and water-insoluble characteristic of Novec into consideration, the biphasic medium of

Table 1. Developed and developing technologies for recovering low temperature heats.

\begin{tabular}{|c|c|c|c|}
\hline Technologies & Thermal Phenomena & Materials & References \\
\hline Hydrogen production & $\begin{array}{c}\text { Critical state } \\
\text { Rayleigh convection }\end{array}$ & Photocatalysts & {$[1]-[4]$} \\
\hline Thermoelectric power generation & $\begin{array}{c}\text { Phase changes } \\
\text { Boiling heat transfer }\end{array}$ & Thermoelectric elements & [5] \\
\hline Liquid turbine power generation & Phase changes & Liquid turbine & [6] this study \\
\hline
\end{tabular}




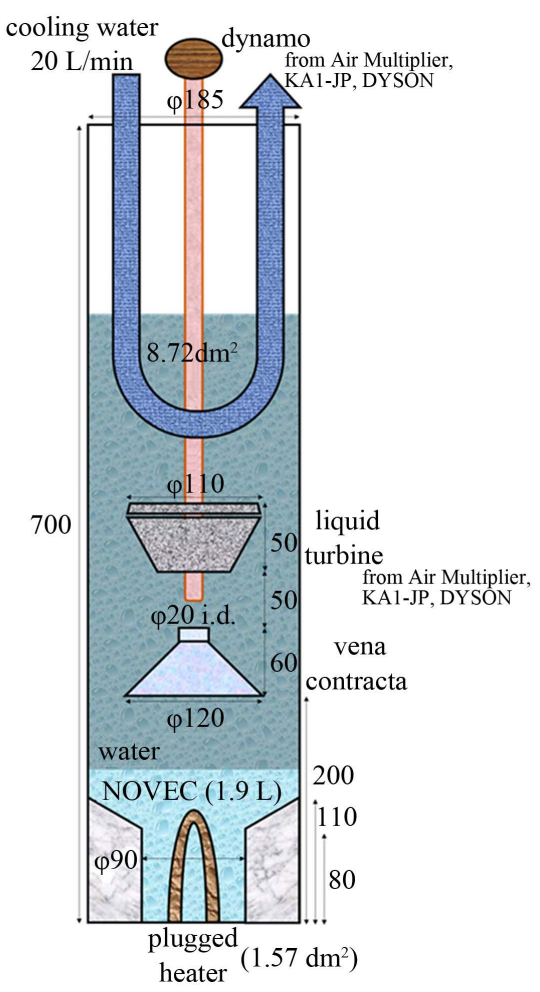

Figure 1. Schematic drawing of proposing liquid turbine power generator.

Table 2. Properties of Novec comaparing with water and other condidates investigated.

\begin{tabular}{cccccccc}
\hline & Novec & & Water & Methanol & Ethanol & Pentane \\
\hline Boiling point $[\mathrm{K}]$ & 307 & $<$ & 373 & 338 & 352 & 309 \\
Specific heat $\left[\mathrm{kJ} \cdot \mathrm{kg}^{-1} \cdot \mathrm{K}^{-1}\right]$ & 1.300 & $<$ & 4.1855 & 2.52 & 2.39 & 2.32 \\
Latent heat of vaporization $\left[\mathrm{kJ}^{\left.-\mathrm{kg}^{-1}\right]}\right.$ & 142 & $<$ & 2254 & 1101 & 838 & 352 \\
Specific density [-] & 1.41 & $>$ & 1.0 & 0.792 & 0.789 & 0.631 \\
Water solubility & Quite low & & - & High & High & Quite low \\
\hline
\end{tabular}

water and the underlying Novec has been justifiably emerged so as to capitalize on each strength of Novec and water. This might be directly linked to high-speed entropy discharge outside the system due to convective heat transfer by water as well as reductions of initial cost and weight of the total system.

Table 3 shows assumed power generating steps via the proposing liquid turbine power generator with Novec/ water biphasic medium grounded on thermal spontaneous phenomena driven by low temperature heats less than $373 \mathrm{~K}$. For a better understanding the assumed power generating steps described in Table 3, Figure 2 show schematics of anticipated thermal spontaneous phenomena during the respective steps denoted in Table 3.

As shown in Table 3 and Figure 2, the surfacing Novec vapor bubbles were expected to accompany the biphasic medium in their wakes. The vena contract a played an important role of gathering the accompanied medium, forming its high momentum flux influent to the liquid turbine, i.e., liquid turbine power generation. Then, Novec vapor bubbles were gradually condensed into droplets, and they precipitated and submerged to the underlying Novec. Eventually, the proposing liquid turbine power generator can be characterized by an open system to ambient but a closed system materially.

\subsection{Experimental Procedures}

Firstly, a set amount of Novec/water biphasic medium was poured into the column-shaped liquid container. A space infilling ABS resin structure as shown in Figure 1 making one revolution around the plugged heater had 


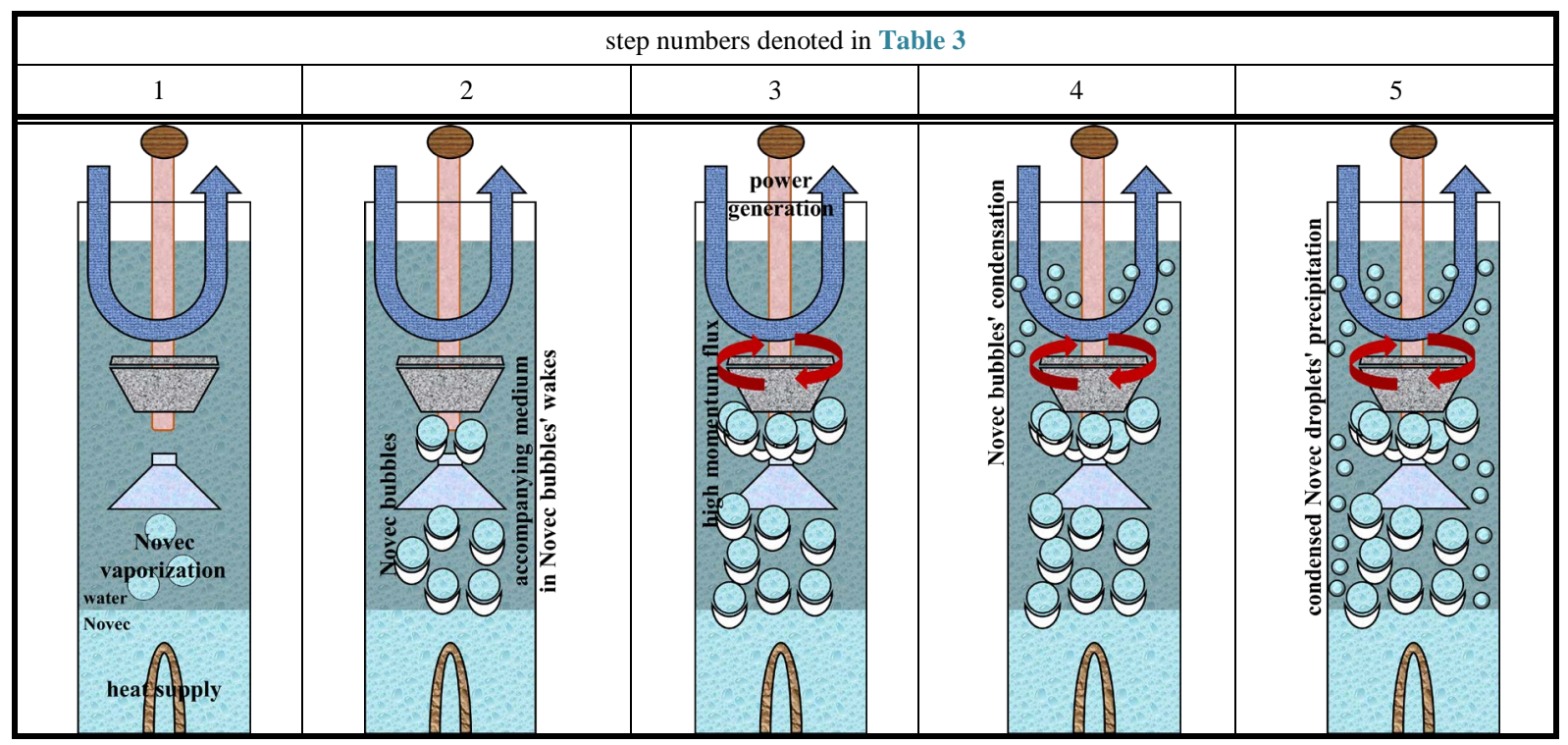

Figure 2. Schematic of thermal spntaneous phenomena.

Table 3. Assumed power generating steps of liquid turbine power generatior.

\begin{tabular}{ccc}
\hline Steps & Operations, inputs and/or thermal spontaneous phenomena & Outputs and/or thermal spontaneous phenomena \\
\hline 1. & Low temperature heats supply to underlying Novec & Novec vaporization (to step 2) \\
2. & Surfacing Novec vapor bubbles with accompanying biphasic medium in their wakes (to step 3) \\
3. & Heat exchange between Novec vapor bubbles and water & Condensation of Novec vapor bubbles \\
4. & Precipitation of condensed Novec dropletsto underlying Novec (to step 1) entropy discharge outside due to convective heat \\
5. & transfer by water
\end{tabular}

been installed at the bottom of the container to reduce the amount of the underlying Novec. Then, the plugged heater could be completely soaked in the underlying Novec with its reduced amount of $1.9 \mathrm{~L}$ throughout the whole experiments. Secondary, a cooling copper tube was submersed into water so as to have a constant heat removal area of $8.72 \mathrm{dm}^{2}$. Thirdly, the plugged heater was energized by using a variable autotransformer. Subsequently, cooling water was circulated through the cooling copper tube. Finally, the generated voltage from a dynamo, which was also pulled out from the commercial air multiplier (KA1-JP, DYSON Limited), was logged for 90 min by an oscilloscope (NR-500, KEYENCE Corporation, Japan) with an uptake-rate of $1.0 \mathrm{MHz}$.

Here, it is well-known that direct current voltages are directly proportional to rotating speeds of turbines. Hence, all the experiments are simply evaluated in terms of respective output voltages generated. As obtained raw output voltages from the dynamo by the oscilloscope included some noises owing to AC power line, static electricity and so on, a Fourier transformation was performed, and the transformed signal was input in band pass filters in order to eliminate all the noises. Then, an inverse Fourier transform was applied to the processed signal, leading to the accurate output voltages to be discussed in the next chapter.

Operating parameters of the proposing liquid turbine power generator are excessively multiple. Because the main purpose of this study was its feasibility demonstrations, experiments were carried out under the highly-selected parameters as summarized in Table 4 together with their practical values tested as well.

\section{Results and Discussion}

\subsection{Feasibility Demonstrations}

First of all, direct current voltages could be universally obtained from the prototype liquid turbine power generator as its name suggests in a great reproducible fashion, irrespective of operating parameters described in Table 4. 
Table 4. Parameters and their tested values.

\begin{tabular}{cc}
\hline Parameters & Values \\
\hline Input heat & 625,680 and $730 \mathrm{~W}$ \\
Cooling temperature & 294,295 and $296 \mathrm{~K}$ \\
Amount of water & 10,11 and $12 \mathrm{~L}$ \\
\hline
\end{tabular}

Anticipated thermal spontaneous phenomena and hydrodynamic behaviors described in Table 3 and Figure 2 were all observed. Therefore, the liquid turbine power generation harvesting low temperature heats can be concluded feasible.

\subsection{Output Voltage versus Input Heat}

Figure 3 shows representative time trends of output voltages from the prototype liquid turbine power generator with various input heats of 625, 680 and $730 \mathrm{~W}$ under a constant cooling temperature $294 \mathrm{~K}$ and amount of water $10 \mathrm{~L}$. It can be seen that the output voltages were unexceptionally increased with time, approaching their respective steady values. In the followings, the output voltages under respective steady states are shown together with their error margins, and discussed.

Figure 4 shows output voltages with various input heats of 625, 680 and $730 \mathrm{~W}$ under a constant cooling temperature $294 \mathrm{~K}$ and amount of water $10 \mathrm{~L}$, which are completely the same conditions as the previous figure. Mean temperatures of water in the vicinity of the liquid turbine under respective steady states are also written in the same figure. It can be seen that the output voltage is exponentially increased towards the input heat. In contrast, the mean water temperature is slightly affected by the input heat. Hence, the proposing liquid turbine power generator is not merely a thermal engine though it is definitely one of the full-fledged thermal engines, of which generated powers normally depend on temperatures. At any rate, it can be concluded that power generations at a little higher than ordinary temperature have been realized by the proposing liquid turbine power generator with Novec/water biphasic medium.

\subsection{Output Voltage versus Cooling Temperature}

Figure 5 shows output voltages with various cooling temperatures of 294, 295 and $296 \mathrm{~K}$ under a constant input heat $680 \mathrm{~W}$ and amount of water $10 \mathrm{~L}$. It is seen that the output voltage is proportionally increased with an increase in the cooling temperature. Therefore, it can be said that the proposing liquid turbine power generator is one of the quite unique thermal engines. Such output voltage increments with increasing the cooling temperature between 294 and $296 \mathrm{~K}$ may be attributed to reducing misspent input heats consumed away as sensible heats of Novec, of which the boiling point is $307 \mathrm{~K}$ as shown in Table 2, under higher cooling temperatures.

Understandably, Novec vapors must be condensed within the system (i.e. inside the operating medium) for long-lasting stable running of the proposing liquid turbine power generator, that is to say, unfettered increments in the cooling temperature are unfavorable. Hence, the optimal cooling temperature is conclusively a little less than the boiling point of Novec, which barely depends on designed values of the system such as heat removal area, medium heights, properties of cooling medium and any configurations.

\subsection{Output Voltage versus Amount of Water}

Figure 6 shows output voltages with various amounts of water in 10, 11 and $12 \mathrm{~L}$ under a constant input heat $680 \mathrm{~W}$ and cooling temperature $294 \mathrm{~K}$. The higher output voltage is attributed to the higher water temperature increased with an increase in the amount of water. This rise in water temperature with increasing the amount of water resulted from increment of accumulated Novec droplets staying on the underlying Novec as superimposed in the same figure as blue solid circles, releasing their sensible heats to water with their higher specific surface area and longer residence time inside water.

Figure 7 shows conceptual drawings of increasing the accumulated Novec droplets staying on the underlying Novec with an increase in amount of water. As described above, such Novec droplets rise water temperature, and are desirable for improving the direct current voltage from the proposing liquid turbine power generator among tested. However, it is appreciated that excessive amount of the Novec droplets staying on the underlying 


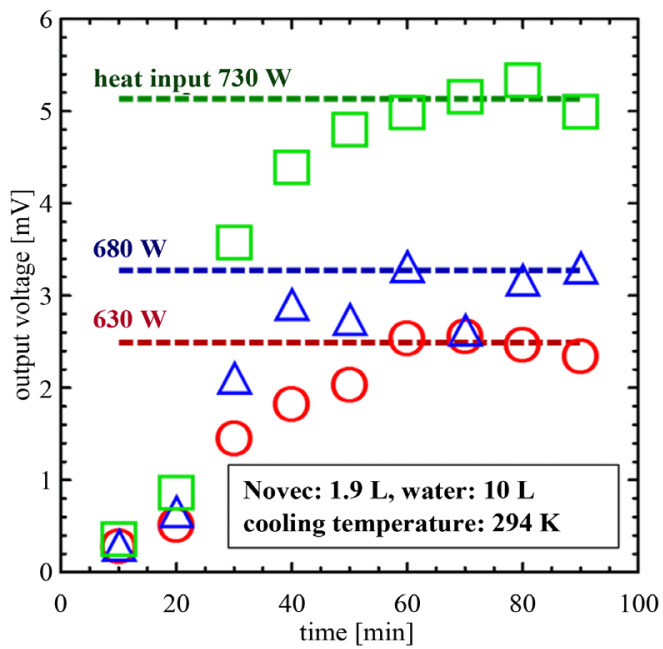

Figure 3. Time trend of output voltage.

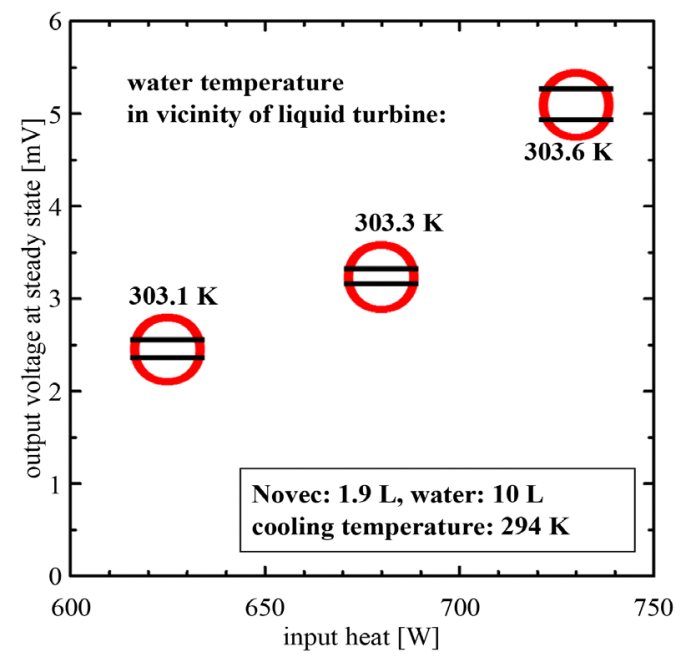

Figure 4. Output voltage with respect to input heat.

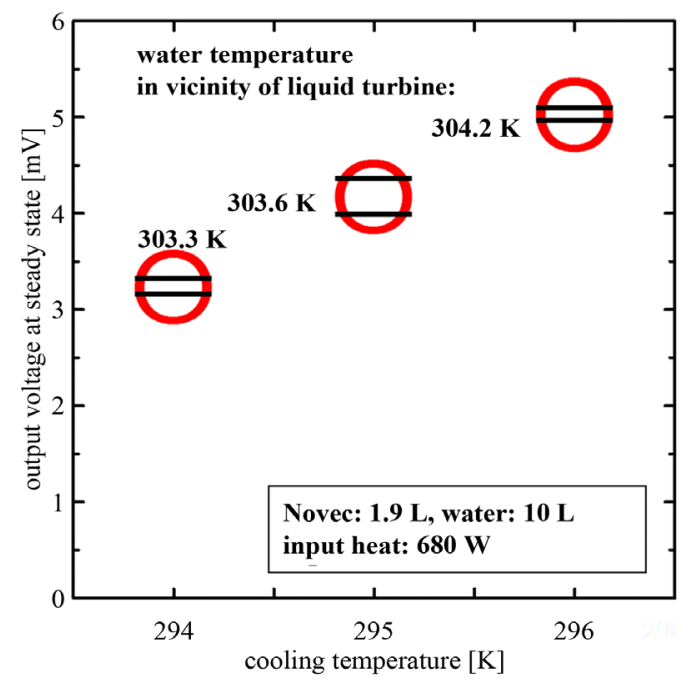

Figure 5. Output voltage with respect to cooling temperature. 


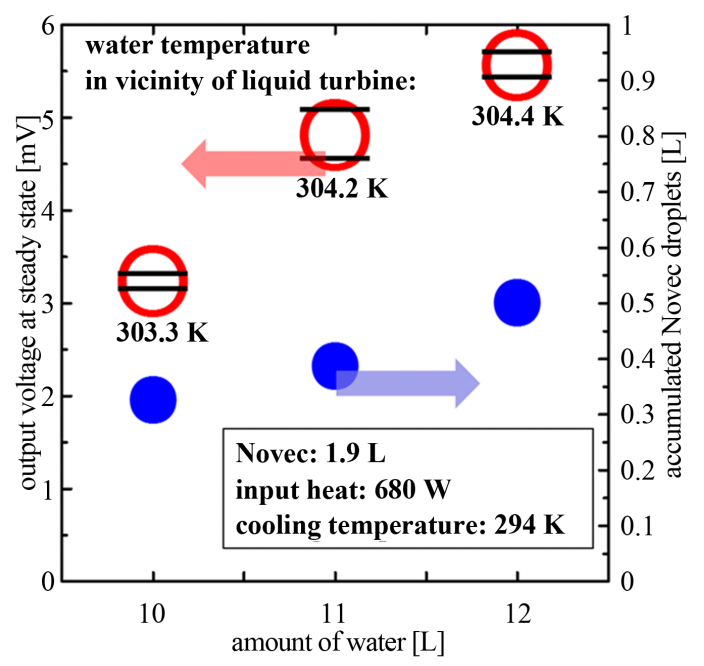

Figure 6. Output voltage with respect toamout of water.

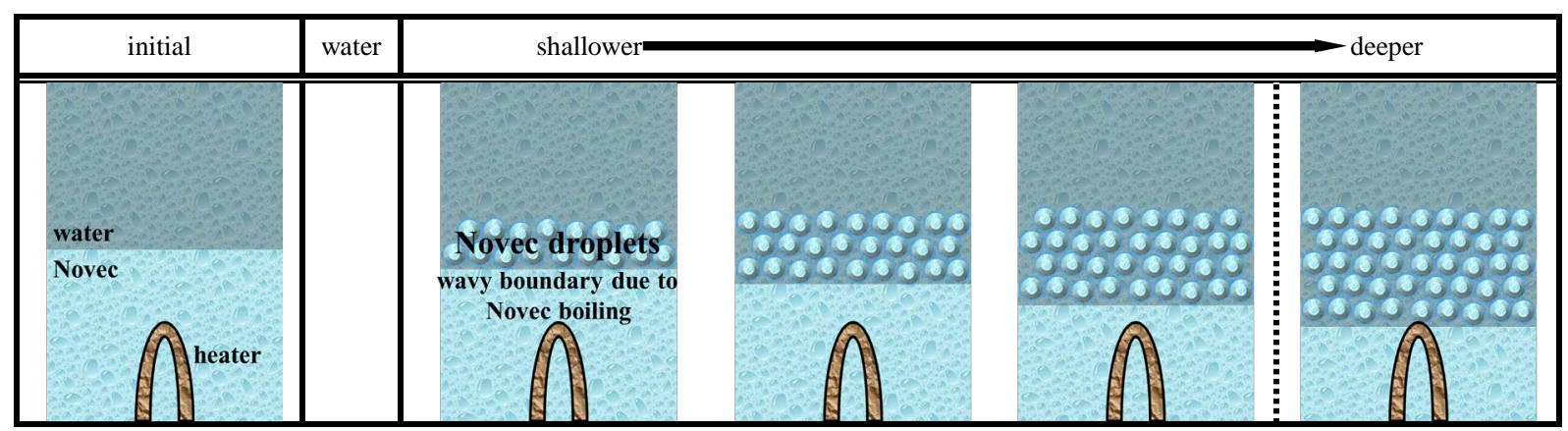

Figure 7. Conceptual drawing of Novec droplets staying on underlying Novec.

Novec must be undesirable since some quantity of heat from the heater, which should be optimally transported to Novec directly, is unfavorably transferred to water surrounding the Novec droplets as well as water on the underlying Novec as illustrated in the rightmost diagram in Figure 7. In order to have high cost-benefit performance and weight reduction of the system, amounts of Novec as well as water must be furthermore reduced. Therefore, the Novec droplets staying on the underlying Novec should be expeditiously incorporated into the underlying Novec for all heat from the heater to be transferred to only Novec even when amounts of Novec and/or water were further reduced. Naturally, theoretical calculations of heat and mass transfers, which remain as future works, must be helpful for the optimal multiphase flow of Novec/water biphasic medium for improving the proposing liquid turbine power generator [16]-[19]. Consequently, increment of the cooling temperature is a better operation for improving the direct current voltage due to rise in water temperature, comparing with much deeper water pouring operation.

\section{Conclusions}

As a new power harvesting technology from low temperature waste heats less than $373 \mathrm{~K}$, a liquid turbine power generator was proposed and developed. The proposing system was mainly composed of a liquid turbine, a liquid container with a biphasic medium of water and an underlying water-insoluble low-boiling-point Novec and heating/cooling sections. Assumed power generating steps via the proposing liquid turbine power generator were as follows:

step 1: the underlying Novec in a liquid phase was vaporized,

step 2: the surfacing Novec vapor bubbles accompanied the water/Novec biphasic medium in their wakes, step 3: such high momentum flux by step. 2 rotated the liquid turbine (i.e. power generation),

step 4: the surfacing Novec vapor was gradually condensed into droplets, 
step 5: the Novec droplets were submerged to the underlying Novec in a liquid phase.

The effects of input heat, cooling temperature and operating medium on the output voltage were experimentally clarified. Power generation at a little higher than ordinary temperature was realized by the proposing liquid turbine power generator with Novec/water biphasic medium. Increasing output voltages could be obtained with increases in the water temperature, the cooling temperature and the amount of water among tested. Then, the proposing liquid turbine power generator is the quite unique thermal engine though it is definitely one of the full-fledged thermal engines.

The experimental data and their speculations indicated further improvements of the direct current voltage from the proposing liquid turbine power generator with Novec/water biphasic medium by means of multiphase flow controls and theoretical calculations. For example, solid powders additions inducing far more vigorous multiphase flow and gross heat capacity enlargements of the operating medium as well as theoretical optimizations of heat and mass transfers are considered the most promising future strategies for improving the proposing system.

\section{Acknowledgements}

This work was supported by JSPS KAKENHI Grant Number JP24656135. This financial support is gratefully acknowledged. The authors would like to thank 3M Japan Limited for the generous supply of Novec. Seiichi Deguchi would like to express deep gratitude to the late Mr. Tatsumi Imura for his kindhearted encouragement and helpful suggestions up until his passing.

\section{References}

[1] Banno, H., Kariya, B., Isu, N., Ogawa, M., Miwa, S., Sawada, K., Tsuge, J., Imaizumi, S., Kato, H., Tokutake, K. and Deguchi, S. (2014) Effect of $\mathrm{TiO}_{2}$ Crystallite Diameter on Photocatalytic Water Splitting Rate. Green and Sustainable Chemistry, Scientific Research, 4, 87-94. http://dx.doi.org/10.4236/gsc.2014.42013

[2] Deguchi, S., Kariya, B., Isu, N., Shimasaki, S., Banno, H., Miwa, S., Sawada, K., Tsuge, J., Imaizumi, S., Kato, H. and Tokutake, K. (2014) Enhancement of Photocatalytic Water Splitting Rate via Rayleigh Convection. Green and Sustainable Chemistry, Scientific Research, 4, 80-86. http://dx.doi.org/10.4236/gsc.2014.42012

[3] Deguchi, S. and Ogawa, M. (2011) Thermal Treatment of Metal-Compound Powders. Japanese Open Patent, No. 2011-202259.

[4] Deguchi, S., Ogawa, M., Nowak, W., Wesolowska, M., Miwa, S., Sawada, K., Tsuge, J., Imaizumi, S., Kato, H., Tokutake, K., Niihara, Y. and Isu, N. (2013) Development of Super- and Sub-Critical Water Annealing Processes. Powder Technology, 249, 163-167. http://dx.doi.org/10.1016/j.powtec.2013.08.013

[5] Ogawa, M., Sawada, K., Shimasaki, S., Ito, M., Banno, H., Miwa, S., Kimoto, K., Sakai, K., Deguchi, S. and Isu, N. (2013) Thermoelectric Power Generating Device. Japanese Open Patent, No. 2013-157432.

[6] Miwa, S., Yamada, A., Imaizumi, S., Sawada, K., Tsuge, J., Kato, H., Tokutake, K., Nakai, Y., Niihara, Y., Isu, N. and Deguchi, S. (2013) Development of Liquid Turbine Power Generator Harvesting Waste Heats. Proceedings of the International Symposium on EcoTopia Science. http://www.esi.nagoya-u.ac.jp/h/isets13/FinalProgram/P-03.htm\#P-3-13

[7] Aswal, D.K., Basu, R. and Singh, A. (2016) Key Issues in Development of Thermoelectric Power Generators: High Figure-of-Merit Materials and Their Highly Conducting Interfaces with Metallic Interconnects. Energy Conversion and Management, 114, 50-67. http://dx.doi.org/10.1016/j.enconman.2016.01.065

[8] Bell, L.E. (2008) Cooling, Heating, Generating Power, and Recovering Waste Heat with Thermoelectric Systems. Science, 321, 1457-1461. http://dx.doi.org/10.1126/science.1158899

[9] David, M.R. (2006) Thermoelectric Waste Heat Recovery as a Renewable Energy Source. International Journal of Innovations in Energy Systems and Power, 1, 13-23.

[10] Angeli, S.D., Monteleone, G., Giaconia, A., Lemonidou, A.A. (2014) State-of-the-Art Catalysts for $\mathrm{CH}_{4}$ Steam Reforming at Low Temperature. International Journal of Hydrogen Energy, 39, 1979-1997. http://dx.doi.org/10.1016/j.ijhydene.2013.12.001

[11] Brown, L.F. (2001) A Comparative Study of Fuels for On-Board Hydrogen Production for Fuel-Cell-Powered Automobiles. International Journal of Hydrogen Energy, 26, 381-397. http://dx.doi.org/10.1016/S0360-3199(00)00092-6

[12] Ma, Y., Guan, G., Shi, C., Zhu, A., Hao, X., Wang, Z., Kusakabe, K. and Abudula, A. (2014) Low-Temperature Steam Reforming of Methanol to Produce Hydrogen over Various Metal-Doped Molybdenum Carbide Catalysts. International Journal of Hydrogen Energy, 39, 258-266. http://dx.doi.org/10.1016/j.ijhydene.2013.09.150

[13] Xu, Y., Ma, Y., Demura, M. and Hirano, T. (2016) Enhanced Catalytic Activity of $\mathrm{Ni}_{3} \mathrm{Al}$ Foils towards Methane Steam 
Reforming by Water Vapor and Hydrogen Pretreatments. International Journal of Hydrogen Energy, 41, 7352-7362. http://dx.doi.org/10.1016/j.ijhydene.2013.09.150

[14] http://www.mmm.co.jp/emsd/fluorine/products/fluorinert.html

[15] http://www.mmm.co.jp/emsd/fluorine/products/novec7000.html

[16] Deguchi, S. (1999) Simulation for Solid Concentration Profile in CFB with Different Fluid/Solid Density Ratios. Chemical Engineering Science, 54, 5507-551. http://dx.doi.org/10.1016/S0009-2509(99)00297-3

[17] Deguchi, S, Deguchi, M. and Nishimura, A. (2003) Development of an Airtight Oscillating Fluidized Bed. Kagaku Kogaku Ronbunshu, 29, 493-498. http://dx.doi.org/10.1252/kakoronbunshu.29.493

[18] Deguchi, S., Mizuno, T., Matsuoka, K., Nishimura, A. and Nasu, H. (2003) Algebraic Expression of the Minimum Gas Velocity Restraining Downward-Flowing Particles through the Contraction Midway of a Circulating Fluidized Bed Riser. Kagaku Kogaku Ronbunshu, 29, 660-666. http://dx.doi.org/10.1252/kakoronbunshu.29.660

[19] Fujisawa, M. and Miura, K. (2009) Volume Preserving Nucleate Boiling Simulation. Visual Computing, 38, $441-448$.

\section{Submit or recommend next manuscript to SCIRP and we will provide best service for you:}

Accepting pre-submission inquiries through Email, Facebook, LinkedIn, Twitter, etc.

A wide selection of journals (inclusive of 9 subjects, more than 200 journals)

Providing 24-hour high-quality service

User-friendly online submission system

Fair and swift peer-review system

Efficient typesetting and proofreading procedure

Display of the result of downloads and visits, as well as the number of cited articles

Maximum dissemination of your research work

Submit your manuscript at: http://papersubmission.scirp.org/ 